study groups $\left({ }^{*} p<.05\right.$ controls vs FA at T0; ${ }^{\circ} p<0.5$ FA at T0 vs FA at T1). Conclusions. ED in children with FA determine an EFA deficiency, in particular for polyunsaturated fatty acids, despite a specific nutritional intervention decided after nutritional counseling.

\begin{tabular}{|l|l|l|l|}
\hline & $\begin{array}{l}\text { Healthy } \\
\text { controls }\end{array}$ & $\begin{array}{l}\text { FA patients } \\
\text { T0 }\end{array}$ & $\begin{array}{l}\text { FA patients } \\
\text { T1 }\end{array}$ \\
\hline Saturated & $34(33-37)$ & $33(32-36)$ & $35(31-36)^{\circ}$ \\
\hline $\begin{array}{l}\text { Monoun- } \\
\text { saturated }\end{array}$ & $22(20-23)$ & $28(27-33)^{*}$ & $30(29-32)$ \\
\hline $\begin{array}{l}\text { Polyun- } \\
\text { saturated }\end{array}$ & $42(40-43)$ & $37(35-38)^{*}$ & $34(31-35)^{\circ}$ \\
\hline $18: 2 n-6$ & $30(29-31)$ & $25(24-28)^{*}$ & $23(21-24)^{\circ}$ \\
\hline $20: 3 n-6$ & $1.6(1.4-2.0)$ & $\begin{array}{l}1.2(1.0- \\
1.7)^{*}\end{array}$ & $\begin{array}{l}1.4(1.3- \\
1.9)^{\circ}\end{array}$ \\
\hline $20: 4 n-6$ & $6.9(5.7-7.2)$ & $\begin{array}{l}5.7(5.4- \\
6.3)^{*}\end{array}$ & $6.4(5.0-7.1)$ \\
\hline $18: 3 n-3$ & $\begin{array}{l}0.28(0.22- \\
0.36)\end{array}$ & $\begin{array}{l}0.33(0.22- \\
0.40)\end{array}$ & $\begin{array}{l}0.24(0.19- \\
0.36)^{\circ}\end{array}$ \\
\hline $20: 5 n-3$ & $\begin{array}{l}0.27(0.16- \\
0.32)\end{array}$ & $\begin{array}{l}0.28(0.19- \\
0.40)\end{array}$ & $\begin{array}{l}0.26(0.13- \\
0.46)\end{array}$ \\
\hline $22: 6 n-3$ & $1.5(1.2-1.8)$ & $1.5(1.2-1.9)$ & $\begin{array}{l}1.3(1.0- \\
1.4)^{\circ}\end{array}$ \\
\hline
\end{tabular}

[Table]

1034

CURRENT PRACTICE OF BREAST MILK FORTIFIER AND SUPPLEMENTS IN NEONATAL UNITS ACROSS ENGLAND

\author{
E. Ginn, M. Ahmed
}

Queen's Hospital Burton, Staffordshire, UK

Background: Preterm infants, especially those with intrauterine growth restriction, have considerably higher nutrient requirements. Research shows that multi-nutrient fortifiers are beneficial in promoting growth. Currently there are no national guidelines on the use of supplementation, with many neonatal units (NNUs) setting their own standards.

Objective: To carry out a survey on sub-regional NNUs across England, looking at current practice in the use of breast milk fortifier and nutrient supplements.

Method: Single operator completed a standardised telephonic questionnaire across 40 NNUs. Ten questions were asked, each with a single option answer, relating to the use of breast milk fortifier and supplements.
Results: The majority (95\%) of neonatal units did not routinely use breast milk fortifier for exclusively breast fed neonates. Of these, 92\% only added breast milk fortifier if the infant was not gaining weight. $23 \%$ of hospitals continued to use breast milk fortifier even if the infants were on a 50:50 mix of breast milk with formula feeds. $50 \%$ of NNUs offered iron supplements if the infant was below 34 weeks gestation. $78 \%$ of NNUs began iron at day 28 of life. Although all NNUs used multivitamins, only $22 \%$ of hospitals routinely used folic acid supplementation. Over $50 \%$ of NNU did not use iron, folic acid or multivitamins if the infant was on exclusive formula feeds.

Conclusion: Despite being a universal tradition, results demonstrate variable practice among NNUs across England. Current use of anecdotal evidence and best guess recommendations highlights the need for collaborative multinational research to produce standardised guidelines.

1035

\section{THE ROLE OF HYPERGLYCEMIA ON NEURODEVELOPMENTAL OUTCOME IN INFANTS OPERATED FOR CONGENITAL HEART DISEASE WITH OPEN-HEART SURGERY}

J. Krueger ${ }^{1,2}$, B. Brotschi ${ }^{1}$, A. Dimitropoulos ${ }^{3}$, C. Balmer ${ }^{4}$, V. Bernet ${ }^{1}$, B. Latal ${ }^{3}$

${ }^{1}$ Department of Neonatology and Pediatric Intensive Care, University Children's Hospital Zurich, Zurich, Switzerland, ${ }^{2}$ Department of Congenital Heart Disease and Pediatric Cardiology

Berlin, Deutsches Herzzentrum Berlin, Berlin, Germany, ${ }^{3}$ Child Development Center, ${ }^{4}$ Division of Pediatric Cardiology, University Children's Hospital Zurich, Zurich, Switzerland

Background: It is unclear whether hyperglycemia after infant cardiac surgery adversely affects neurodevelopmental outcome.

Methods: Secondary analysis of a prospective cohort study on neurodevelopmental outcome after infant cardiac surgery. Exclusion criteria were: older than one year of age at first surgery, genetic disorders or dysmorphic syndromes and birth weight $<2000$ grams and postoperative death. Of 368 children, 172 met inclusion criteria. Ten children did not yet return for the one year follow up examination and two were lost to follow-up. Follow-up examination at four years was available for 56 children, the 
remaining children were too young. Postoperative highest and lowest glucose levels within 24 hours after bypass surgery were prospectively collected. Neurodevelopmental outcome at one year of age was assessed with the Bayley Scales of Infant Development II (Mental Developmental Index-MDI, Psychomotor Developmental Index-PDI) in 160 children and at four years with the WPPSI.

Results: Mean age at surgery was 2.9 months (0.1-10.7 months). Mean highest postoperative glucose values were 12.76 (SD 4.9), mean lowest were 6.82 (SD 1.9). Glucose values normalized in all children within 48 hours, seven children (4\%) received insulin infusions. Postoperative highest and lowest glucose levels were not associated with neurodevelopmental outcome at one year or at four years, whereas more abnormal preoperative neurological findings were associated with poorer one-year outcome (MDI $p<0.001, \mathrm{PDI}=0.03$ ).

Conclusion: In our population glucose values normalized within 48 hours and had no adverse effect on neurodevelopmental outcome.

\section{6}

\section{GROWTH FAILURE AT 3 YEARS OF CORRECT AGE IN CHILDREN BORN BELOW 31 WEEKS GESTATION: PREVALENCE AND RISK FACTORS}

\author{
F. Serrao, F. Gallini, L. Maggio, S. Costa, F. Cota, \\ C. Romagnoli
}

Division of Neonatology -Department of

Paediatrics, University Hospital "Agostino

Gemelli"- Catholic University Sacred Heart, Rome, Italy

Background and aims: Early growth failure in extremely preterm infants is associated with negative long term outcomes. The aim of this study was to report the prevalence and postnatal risk factors of growth failure at 3 years correct age (c.a.) among children born below 31 wks GA

Methods: Anthropometric measures and background information of 133 AGA infants with GA $\leq 30$ weeks were collected during their stay in $\mathrm{NICU}$ and then in a follow up program planned until 3 years c.a. Growth failure (GF) at 3 years was defined as a $z$ score $<-1.28$.

Results: At 3 years c.a the GF prevalence was $45.9 \%$ for weight, $34.6 \%$ for height and $30.3 \%$ for head circumference. Infants with weight growth failure (WGF) were similar to controls (C) for GA $(27,7 \pm 1.4$ vs $27,8 \pm 1,6$ wks), BW (1026 \pm 200 vs $1006 \pm 219 \mathrm{~g}$ ), nutritional intakes, main clinical and growth outcomes during the NICU stay. Multiple logisitic regression analysis showed that Zscore variation from birth to discharge was independently associated to WGF (OR $0.30,95 \% \mathrm{Cl} 0.16-0.56$ ) and HC GF (OR 0.29, 95\%Cl 0.14-0.56).

Conclusions: These data suggest that, in our population of ELBW infants, the early postnatal growth is an important prognostic factor of growth at least up to 36 months c.a.

\section{7}

\section{MOTHER-CHILD ROOMING-IN FOR PRETERM AND LOW BIRTH WEIGHT NEONATE AT OUR MATERNITY WARD}

\author{
H. Yoshio ${ }^{1}$, Y. Yokoi ${ }^{2}$, Y. Yamauchi \\ ${ }^{1}$ Neonatology, St. Marianna University School of \\ Medicine, Kawasaki, ${ }^{2}$ Neonatology, Okayama \\ Medical Center, Okayama, Japan
}

Backgroud and aims: The goodness of roomingin for term baby has already been considered to promote breastfeeding and the mother and child relationship. However, not many reports have been published about from how much birth weight or how low gestational ages we should start rooming-in just after birth. We evaluated the possibility and efficacy of mother and child rooming-in together soon after birth for near term or low birth weight (LBW) neonate.

Methods: The healthy inborn preterm and LBW neonates were enrolled and divided into three groups, namely Group A (13 cases), Group B (42 cases) and Group C (99 cases). The birth weights (BWs) of Group A and B were larger than $2 \mathrm{~kg}$ and their gestational ages (GAs) were 35 and 36weeks, respectively. Group C consisted of term and LBW neonates heavier than $2 \mathrm{~kg}$ of BW.

Results: The number of infants from Group A, B and $C$ that discharged from hospital through roomingin were $9 / 13(69 \%), 36 / 42(86 \%)$ and $96 / 99(97 \%)$, respectively. The exclusive breastfeeding rates of Group A, B and C at the time of hospital discharge were $56 \%, 69 \%$ and $85 \%$, respectively, and also they had good weight gains at one month of age.

Conclusions: This study showed that the roomingin for both near term (35 and 36weeks of GA) and term, LBW neonates over $2 \mathrm{~kg}$ of BW seems to be 